\title{
El estado abierto: el pensamiento de Karl R. Popper en la obra de Peter Häberle ${ }^{1}$
}

\section{The Open State: The Thinking of Karl R. Popper in the Work of Peter Häberle}

Pedro Daniel González Rivas Martínez²

Fecha de Recepción: 9 de marzo de 2016

Fecha de Aprobación: 7 de junio de 2016

\section{RESUMEN}

El objetivo primordial del presente texto es coadyuvar a la comprensión de la ideología académica del constitucionalista alemán Peter Häberle. Para alcanzar un entendimiento consistente de su obra es necesario tener como presupuesto el trabajo de varios pensadores de importancia histórica en los que Häberle fundamentó su pensamiento; este texto se ocupa exclusivamente y parcialmente de uno de ellos: Karl Raymund Popper. Häberle reconoce abiertamente que su obra ha sido realizable gracias a los trabajos de Popper y remite con frecuencia a los mismos, en ocasiones dando por supuesto su conocimiento, por lo que conviene explicitar algunas nociones fundamentales, así como la forma en que operan la recepción y aplicación de las mismas.

Palabras clave: K. Popper, P. Häberle, sociedad abierta, racionalismo crítico, Estado constitucional.

1 El artículo es producto del proyecto de investigación institucional de la Universidad Autónoma de Querétaro, México, titulado: "El Estado Abierto y sus amigos".

2 Magister en Derecho y Doctorando en Derecho por la Universidad Autónoma de Querétaro, México. Docente e Investigador de la citada Universidad. Correo electrónico: pdanielgrm@hotmail.com 


\begin{abstract}
The main purpose of this text is to aid in the comprehension of the academic ideology of the German constitutionalist Peter Häberle. In order to have a coherent understanding of his work it is necessary to take into account the presumption of the works of several thinkers of historic relevance on which Häberle based his thinking; here we will be talking about one of them: Karl Raymund Popper. Häberle publicly acknowledges that his work was possible thanks to the work of Popper and frequently refers to him, occasionally taking for granted that the reader possesses that knowledge, therefore it is advisable to explain some of the fundamental notions, and how the learning and application thereto is performed.
\end{abstract}

Key words: K. Popper, P. Häberle, open society, critical rationalism, Constitutional Sate.

\title{
I. INTRODUCCIÓN.
}

La Sociedad Abierta de Karl R. Popper es una estructura teórica a partir de la cual Peter Häberle desarrolla su obra académica; algunos de sus elementos le sirven como guías para su labor científica y como inspiración para el desarrollo de teorías y conceptos propios. Häberle expresa de manera reiterada y abierta que gran parte de su obra ha sido realizable gracias a los trabajos de Popper y remite con frecuencia a los mismos, casi siempre dando por supuesto su conocimiento, por lo que, si se pretende comprender la obra häberleana, conviene explicitar algunas nociones fundamentales, así como la forma en que operan la recepción y aplicación de las mismas. El presente trabajo no tiene pretensiones de exhaustividad, solo busca abordar ciertos puntos de contacto básico y ejemplificar con algunos casos esclarecedores que, sin embargo, permitan sustentar las siguientes afirmaciones:

A. La propuesta metodológica y conceptual de Peter Häberle constituye un desarrollo congruente de la filosofía epistemológica y teórico-política de Karl R. Popper. Es decir, que la Sociedad Abierta de Popper conforma, de manera principalísima, la cimentación del Estado Constitucional häberleano.

B. Para Häberle, el Estado constitucional y la actividad de quienes ordenan sus partes se encuentran regulados íntegramente por el racionalismo crítico popperiano. 
C. Para Häberle, los componentes de la Sociedad Abierta son las premisas del arquetipo Estado constitucional.

El trabajo tiene como sustento, por una parte, el estudio de tres trabajos principales en la obra de Karl R. Popper, a saber, La Sociedad Abierta y sus Enemigos, la Lógica de la Investigación Científica y, finalmente, Conjeturas y Refutaciones, y, por otra parte, el estudio contrastado de la obra de Peter Häberle en general, pero, principalmente, de los siguientes textos: El Estado Constitucional, Verdad y Estado Constitucional y Constitución como Cultura.

\section{LA SOCIEDAD ABIERTA Y EL RACIONALISMO CRÍTICO}

\section{El racionalismo crítico de Popper y la teoría constitucional propuesta por Häberle.}

En su obra denominada La sociedad abierta y sus enemigos, Popper (2006) realiza la descripción de un modelo o arquetipo cultural cuyos fundamentos son la razón, la libertad y la igualdad humanas. En dicho trabajo, la exposición de los elementos que la componen se realiza contrastándolos con los rasgos de lo que llama la "so-

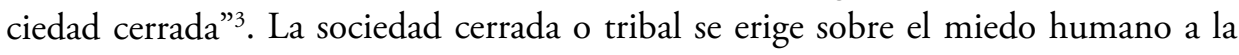
incertidumbre y el apego al dogma, a la autoridad y a la tradición como medios para adquirir certeza, mientras que el racionalismo crítico es el elemento que estructura a la sociedad abierta. Puede decirse que la sociedad abierta es primariamente una sociedad en la que la razón crítica opera en todos los ámbitos de la vida humana. El juego argumentativo del racionalismo crítico es en última instancia un modelo epistémico, es decir, un mecanismo para generar y acumular conocimiento científico. ${ }^{4}$ Ello es posible gracias a que, como señala Popper (2006), "la actitud de la razonabilidad es

3 Se ha publicado, por el mismo autor del presente artículo, una síntesis de la obra de Popper referida, misma que se puede encontrar en: Jiménez Gómez, Juan Ricardo (coordinador), Revolución Mexicana, Constitución de 1917 y Neoconstitucionalismo, El bajo nivel de constitucionalidad en México como un problema cultural, México, Instituto de Estudios Constitucionales, Universidad Autónoma de Querétaro, México, 2006.

4 La descripción del modelo es exhaustiva en varias obras de Popper, las más importantes son: La sociedad abierta y sus enemigos y La lógica de la investigación científica; aunque también se pueden encontrar desarrollos de varios de sus elementos y ejemplos de su uso en Conjeturas y refutaciones. 
muy semejante a la actitud científica”. Y como sucede con todo juego, la adopción de sus reglas depende de una convención. En el caso que nos ocupa, nuestro pensador receptor, es decir, Peter Häberle, declara que participa del juego descrito cuando afirma: "ejerzo autocrítica en mi trabajo científico, eligiendo todas las formulaciones de manera provisional, adoptando de Popper su procedimiento trial-and-error" (Valadés, 2006, p.143), mientras que la revisión y ajuste de las propias teorías por parte del autor a lo largo de su vida académica dan cuenta de su afección al paradigma referido, ${ }^{5}$ por lo que es razonable la afirmación de que dicho esquema de racionalidad es el sustento básico de la investigación académica de Peter Häberle.

Aunado a la actitud autocrítica descrita, un dato que confirma la postura reflexiva de Häberle es que no se adhiere de manera dogmática a la obra de Popper; a lo largo de su producción, se pueden encontrar varios ejemplos de juicios adversos a distintas estructuras teóricas de este autor, ${ }^{6}$ lo cual corrobora que Häberle trabaja sistemáticamente practicando las reglas de racionalismo crítico, incluso cuando se trata del análisis de la obra del mismo creador de esa teoría epistemológica.

Pero Häberle no solamente se declara partidario del racionalismo crítico en cuanto a su propia actividad académica a través de la autocrítica, sino que la propone como paradigma para el quehacer de los miembros de la comunidad científica que trabaja en el desarrollo de los elementos del arquetipo Estado constitucional. Esto queda de manifiesto cuando afirma: "La comunidad de especialistas de un país y, cada vez más la de una región... debería estar desarrollando modelos teóricos constantemente y ponerlos a debate, como propone el racionalismo crítico de Popper" (Valadés, 2006, p. 13), idea que lleva a la globalidad cuando se refiere a "la república internacional de los estudiosos" (Valadés, 2006, p. 185).

5 Un ejemplo respecto de esta actitud en Häberle se encuentra en la obra Teoría de la Constitución como ciencia de la cultura, la cual se presenta en su segunda edición con una gran cantidad de revisiones, ajustes y desarrollos. Otro caso también ilustrativo es el texto El Estado constitucional, el cual presenta muchas de sus nociones, previamente elaboradas de forma aislada, en una codificación que demandó la sistematización, revisión y ajuste de varios conceptos con el ánimo de actualizarlos al estado de la cuestión.

6 Ejemplos de este ejercicio crítico sobre la obra de Popper pueden encontrarse en: Häberle, Peter, Verdad y Estado constitucional, traducción de Guillermo José Mańón Garibay, México, unam, 2006, pp. 11-12; VALADÉS, Diego (compilador), Conversaciones académicas con Peter Häberle, México, Instituto de Investigaciones Jurídicas, unam, 2006. pp. 48-49, 139; Häberle, Peter, El Estado constitucional, trad. de Héctor Fix Fierro, México, Instituto de Investigaciones Jurídicas, UNAM, 2003, pp. 304-305. 
Pedro Daniel González Rivas Martínez

La eterna persecución intersubjetiva de la verdad y la justicia es propuesta por Häberle cuando declara que "el Estado constitucional como tipo forma parte del credo de este trabajo... podemos trabajar en el sentido de técnica incremental de Popper, de modo que el Estado constitucional... sea entendido como res pública semper reformanda" (Häberle, 2003, p. 295). La teoría constitucional desarrollada y propuesta por Häberle para los estudios constitucionales contemporáneos construye y define su objeto de investigación al utilizar el modelo de racionalidad descrito por Popper.

\section{El racionalismo crítico y el Estado constitucional}

Häberle da el paso definitivo en su propuesta de la adopción del modelo del racionalismo crítico cuando afirma - tanto de manera implícita como en forma expresa- que las reglas del juego racional invaden todos los ámbitos de la dinámica social en un Estado constitucional. En este apartado se presentan las pruebas que corroboran dicha tesis.

En la sociedad abierta encontramos que las reglas del racionalismo crítico no solo norman el ámbito académico, sino que este mecanismo se aplica para resolver todas las cuestiones sociales, buscando eliminar el uso de la fuerza y la violencia entre los hombres. Popper sostiene que la cultura abierta o democrática contiene entre sus mecanismos básicos los de la razón y "proporciona un marco institucional capaz de permitir las reformas sin violencia" (Popper, 2006, p. 18), "a través del debate crítico en el que nuestras batallas se libran con palabras en lugar de con armas" (Popper, 2006, p. 807). Igualmente, expresa que la "actitud de la razonabilidad" es muy semejante a la actitud científica, a la creencia de que en la búsqueda de la verdad necesitamos cooperación y que, con la ayuda del raciocinio, podremos alcanzar, con el tiempo, algo de objetividad" (Popper, 2006. p. 438). A lo largo de la obra referida expresa razonadamente las consecuencias de la adopción del racionalismo crítico dentro de la cultura democrática; el resultado son todos los rasgos de la cosmovisión abierta que describe en su obra, con lo que resulta patente que el racionalismo crítico es el elemento que da piso y estructura a la cultura de la sociedad abierta; se trata de la "civilización que se basa en la ciencia" (Popper, 2008, p. 191).

En efecto, si tomamos en cuenta que Häberle afirma que el Estado constitucional es la organización estatal congruente con la cultura descrita y denominada por Popper 
como "Sociedad abierta", 7 es válido deducir que para Häberle el Estado constitucional se encuentra impregnado íntegramente de racionalismo crítico. Esta tesis también haya fundamento en múltiples afirmaciones hechas por Häberle a lo largo de su obra; a continuación se refieren algunas de las más importantes, mismas que se presentan atendiendo a la amplitud del ámbito respectivo y en orden incremental:

"El voto particular en los tribunales constitucionales es la manifestación institucionalizada procesalmente, de la idea de que las normas jurídicas dejan abiertas posibilidades y alternativas de interpretación y que la alternativa que hoy se escoge no puede excluir otras alternativas en el futuro" (Häberle, 2003, p. 53).

Cita en la que, tratándose de interpretación jurisdiccional, se trasluce el respeto a varias reglas del racionalismo crítico, tales como la apertura constante a todo argumento refutador, la permanente derrotabilidad del argumento ganador, la infinitud del juego, la publicidad e intersubjetividad del juego y el falibilismo progresivo.

"La apertura hacia las alternativas debe existir efectivamente, por lo que en este punto los ordenamientos democráticos han de someterse continuamente a la crítica" (Häberle, 2003, p. 51). Texto que, en relación con el tema de los sistemas jurídicos, refiere al principio fundamental de la revisabilidad y derrotabilidad respecto de cualquier orden normativo y sus partes.

"Los procedimientos de ensayo y error... nos auxilian... en nuestra aproximación a la verdad, tanto en el ámbito científico como en el político" (Häberle, 2003, p. 31). Ampliando el espectro de aplicación del principio de avances fragmentarios a partir de conjeturas y refutaciones a los asuntos cívicos en general.

"La virtud democrática... como expresión de la tolerancia y el pluralismo... es una manifestación específica del racionalismo crítico, con su postulado de

7 Häberle (2002, p. 75), texto en el que el autor afirma: "El susodicho pensamiento posibilista representa el troquel específico que configura el racionalismo crítico junto con el omnipresente postulado de falsabilidad popperiano respecto de conjeturas y refutaciones. En todo caso esta forma de filosofía alternativo-posibilista presupone un modelo de constitución siempre abierto, como también abierto debe ser el modelo de Estado, el de sociedad y el de pensamiento...". 
la falsabilidad, de las conjectures and refutations. El pensamiento de las posibilidades presupone apertura de la Constitución, del Estado, de la sociedad, del pensamiento, y crea al mismo tiempo dicha apertura. Su padrino es el racionalismo crítico, el pensamiento liberal (transformado) en alternativas" (Häberle, 2003, p. 54).

Es decir que, para Häberle, el Estado constitucional, con su rasgo democrático ineludible, implica la operación generalizada del racionalismo crítico en todos los ámbitos de la vida social. En el Estado constitucional, la virtud cívica implica el manejo permanente del racionalismo crítico como mecanismo para encontrar las soluciones a los problemas sociales, con lo que se corrobora la tesis de que, para Häberle, el Estado constitucional tiene como rasgo cultural primario el juego argumentativo descrito originalmente por Popper.

Cerraremos esta apartado con la siguiente cita de Häberle que, después de lo dicho hasta el momento, resulta esclarecedora:

"El Estado constitucional se contrapone a cualquier tipo de Estado totalitario del color que sea, a cualquier ambición de verdad absoluta o a cualquier monopolio de información e ideología totalitaria. Su caracteristica más importante reside en no dar cabida a la verdad absoluta, sino en encontrarse permanentemente en búsqueda de la misma. De igual modo, puede decirse que se erige sobre la reemplazabilidad y perceptibilidad de cualquier verdad, entendiendo esto fundamentalmente en plural y no en singular, y sin imponer nada.

La idea de K.R. Popper sobre la sociedad abierta, o sea su racionalismo crítico, presenta de la mejor manera en palabras y procesos la relación del Estado constitucional con el problema de la verdad considerándolo dentro de sus contextos culturales." (Häberle, 2006, pp. 113-114).

\section{LA SOCIEDAD ABIERTA Y EL TIPO ESTADO CONSTITUCIONAL}

El llamado iusculturalismo, utilizado por Peter Häberle en sus estudios constitucionales, no es otra cosa que el estudio desde una perspectiva jurídico-política de la cul- 
tura descrita por Popper como sociedad abierta. Así como la sociedad abierta es un paradigma sociocultural, el Estado constitucional es un arquetipo jurídico-político de esa misma cultura. Ambos tienen el mismo objeto pero difieren en la postura teórica desde la que abordan el objeto de estudio; Popper hace el análisis desde un ángulo enteramente sociológico, observa una colectividad de hombres, mientras que Häberle observa los aspectos que constituyen una comunidad de ciudadanos. Popper estudia la cultura humana en general; Häberle se concentra en su aspecto jurídicopolítico. Por ello, para Häberle "la constitución es una parte de la cultura" (Häberle, 2003 , p. 21). Es en este sentido que Häberle habla de las sociedades abiertas como aquellas que son constituidas en forma de Estados constitucionales (Häberle, 1997, p. 328) y de la constitución del Estado constitucional como aquella que registra la sociedad abierta (Häberle, 2006, p. 76). En el estudio de la influencia de Popper en Häberle debe observarse que la sociedad abierta del primero es previa y más amplia que el Estado constitucional del segundo; puede haber hombres sin ciudadanos pero no viceversa. Es así que la teoría constitucional de Häberle es "una teoría constitucional de la sociedad abierta" (Häberle, 2003, p. 54).

El propio Häberle y algunos de sus estudiosos han descrito cómo es que se conforma el tipo Estado constitucional ${ }^{8}$; prácticamente consiste en identificar aquellos elementos típicos en las constituciones democráticas (entendiendo a estas como los textos y sus respectivos contextos culturales), aquellos rasgos que por su pertinencia y persistencia se vuelven indispensables para una cultura constitucional con pretensiones democráticas. ${ }^{9}$ Se puede corroborar fácilmente que este catálogo proviene de dicho

8 Una descripción detallada de la técnica de construcción del tipo Estado constitucional puede encontrarse en: González Rivas Martínez, Pedro Daniel, "Una aproximación al Iusculturalismo de Peter Häberle”, Cuestiones Constitucionales, Revista Mexicana de Derecho Constitucional, Instituto de Investigaciones Jurídicas, UNAM, México, núm. 27, julio-diciembre de 2012, p. 165.

9 Según Häberle, el catálogo de los elementos típicos del Estado constitucional contemporáneo es el siguiente: la dignidad humana como premisa, la garantía de los derechos humanos fundamentales, el principio de igualdad, la democracia efectiva, el principio del pluralismo, el principio de la tolerancia, el principio de la soberanía popular, el principio de laicidad o imparcialidad del Estado, la Constitución como contrato, el principio de la división de poderes, el federalismo o regionalismo, los principios del Estado de Derecho, del Estado social y del Estado cultural, la independencia de la jurisdicción, la pluralidad de partidos, la protección de minorías, el principio de desarrollo sustentable ecológicamente, la jurisdicción constitucional, la supremacía constitucional, la vigilancia ciudadana de los derechos humanos, la economía social de mercado, la protección del medio ambiente, la protección de las culturas autóctonas, órganos defensores del pueblo, la Constitución escrita... Este 
proceso de comparación de los textos constitucionales, pretendidamente democráticos, pero debe observarse que la interpretación de esos textos, con el debido rigor, no puede realizarse sin la estructura conceptual y argumentativa de los textos clásicos o paradigmáticos de aquellos que han explicitado los rasgos de la cultura democrática. Häberle cita a muchos de esos autores clásicos, entre los cuales ubica principalmente a Popper; esto obedece a que, para Häberle, la obra de Popper constituye el estado de la cuestión de varios aspectos fundamentales de la cultura democrática en general.

La labor de los constitucionalistas descrita por Häberle como política científica de reservas estriba primeramente en identificar los elementos del tipo, pero la parte sustantiva de ese trabajo consiste en dar sentido a las palabras que los refieren, en dotarles de contenido semántico: para ello es que la sociedad abierta de Popper sirve en la obra de Häberle. Cuando Häberle dice "democracia" se refiere a una sociedad regida por el institucionalismo, el control de los órganos del Estado por parte del pueblo, el intervencionismo equilibrado, los procesos cívicos racionales y la ingeniería social parcial y gradual; cuando Häberle sugiere la persecución de una "comunidad universal de Estados constitucionales cooperativos" se refiere a la estructura jurídica de una sociedad abierta universalizada; cuando dice Estado constitucional o democracia pluralista tiene en mente a la sociedad abierta ${ }^{10}$ descrita en un pacto constituyente. $\mathrm{Y}$, aun más importante, cuando desarrolla sus estructuras conceptuales, lo hace estableciendo como premisas los rasgos de la sociedad abierta y, en el armazón institucional resultante, los genes culturales de esa cosmovisión son plenamente respetados; todos los elementos del tipo Estado constitucional, en el desarrollo teórico que Häberle lleva a cabo, son congruentes con los elementos de la sociedad abierta. Esta tesis se corrobora a nivel intuitivo con el estudio general contrastado de la obra de ambos autores; sin embargo, dadas las intenciones racionalizadoras de este texto, en el siguiente apartado se procede a exponer puntualmente cómo es que esto opera; lo haremos únicamente respecto de una sección en que las dos estructuras teóricas hacen contacto claramente; se trata del asunto del pluralismo.

listado proviene de múltiples obras del referido autor, si bien en Häberle, 2003, pp. 1-2, se puede encontrar una lista más o menos extensa, aunque no exhaustiva.

10 Ejemplos claros al respecto se encuentran en: Häberle, 2003 págs. 3, 4, 35-36, 68, 197. 


\section{Sociedad plural y Constitución democrática}

Uno de los casos en que es patente que Häberle busca tejer una urdimbre institucional que permita la proyección y protección de los elementos de la sociedad abierta es el del pluralismo. Para clarificar esta operación nos serviremos del caso de la relación entre la sociedad pluralista de Popper y la Constitución democrática de Häberle. En primera instancia, haremos referencia específica a algunos rasgos de la sociedad abierta descrita por Popper y después observaremos el desarrollo teórico realizado por Häberle a partir de los mismos. En cuanto a la descripción de la sociedad abierta, utilizaremos el recurso de contrastación con la sociedad cerrada.

\section{La homogeneidad de la cultura tribal vs. El pluralismo de la cultura abierta}

Revisemos con detenimiento algunos de los rasgos de la sociedad cerrada o tribal, con el objetivo de corroborar que en este modelo cultural no hay cabida para el pluralismo, sino solo para la conformidad. En la descripción de la cultura cerrada, Popper señala cuatro elementos que dan sustento a la visión tribalista de la sociedad: A) la concepción colectivista de la sociedad y la justicia, B) la teoría organicista del Estado, C) la tradición autoritaria de la verdad, y D) las concepciones utopistas de las sociedades humanas.

A. La concepción colectivista de la sociedad y la justicia parte de la idea del contrato social en beneficio de los individuos participantes, quienes no se bastan por sí mismos (Popper, 2006, p. 92.), si no que es la sociedad el mecanismo que permite al hombre su realización. Así, la colectividad constituye el supremo valor, ya sea la tribu, el clan o la clase; mientras que el individuo no significa nada en absoluto si no es con referencia a dicho grupo (Popper, 2006, p. 24). Se estima que el individuo debe todo a la organización social, su existencia física y espiritual (Popper, 2006, p. 248); es por ello que el individuo se encuentra obligado a su consagración absoluta en favor del grupo, clase o nación (Popper, 2006, p. 285). En efecto "la utilidad colectiva constituye la consideración ética fundamental" (Popper, 2006, p. 154), y el interés colectivo domina la vida del individuo (Popper, 2006, p. 155). Se tiene la obligación 
Pedro Daniel González Rivas Martínez

institucional de enseñar a los miembros que lo justo es aquello que es benéfico para los intereses de la colectividad, sin importar la suerte de cada individuo (Popper, 2006, pp. 211, 487).

Respecto de la responsabilidad ética, esta recae solo en las instituciones, ya que el proceder individual se encuentra gobernado por convenciones acríticas, no por decisiones personales racionales (Popper, 2006, pp. 188-189, 266).

B. La teoría organicista del Estado parte del valor supremo de la colectividad, le asigna aspiraciones ideales (Popper, 2006, p.101) y pretende que opere como un organismo unificado y armonioso (Popper, 2006, pp. 95, 118, 123). En aras de esa armonía orgánica, cada individuo debe respetar su función natural dentro del cuerpo social (Popper, 2006, pp. 155, 269), que se compone de clases de hombres que realizan las funciones que naturalmente les corresponden; hay, básicamente, gobernantes y gobernados. Los gobernantes realizan la función elemental de pastorear sabia y severamente al rebaño gobernado (Popper, 2006, pp. 65, 69, 95, 101) y de mantener la salud del organismo colectivo, evitando así la disolución social, la cual equivale a la muerte (Popper, 2006, p. 155). La estratificación estrictamente disciplinada de toda la estructura social permite que cada miembro de la comunidad contribuya de manera adecuada a la operación perfecta del sistema (Popper, 2006, p. 118). La decadencia del organismo social proviene de la degradación moral de sus elementos individuales y del rompimiento del orden ideal. Dicha degeneración es provocada por la mezcla de castas, por lo que esta debe evitarse para proteger el bien social integral (Popper, 2006, pp. 96-97). En efecto, la homogeneidad cultural es un mecanismo que permite la unidad y estabilidad del sistema, la comunidad cultural de estos valores coadyuva para que cada individuo comprenda y valore su papel dentro del sistema y no pretenda modificar el orden natural ideal. Por ello, tanto la iniciativa individual como el ejercicio de la autonomía particular, en todos los ámbitos, deben suprimirse (Popper, 2006, pp. 118-119, 151); la finalidad de las diversas entidades sociales básicas como la educación, la ley y el control gubernamental es cumplir con estas funciones (Popper, 2006, pp. 95, 155). 
C. La tradición autoritaria de la verdad resulta el paradigma congruente con la sociedad tribal. Las instituciones políticas son las autoridades que determinan cuál ha de ser considerada la verdad objetiva (Popper, 2006, p. 259) en razón del bien social general. Esta verdad es utilizada para fundamentar tanto el orden normativo como el proceder individual y grupal, con lo que la responsabilidad sobre las decisiones políticas se diluye en la colectividad (Popper, 2006, p. 189). Los medios para hacer prevalecer esta verdad en las masas gobernadas son la propaganda (Popper, 2006, p. 155) y, en caso necesario, la fuerza. La iniciativa individual, la innovación, la creatividad y el libre ejercicio de la autonomía son enemigos de este modelo de pensamiento (Popper, 2006, pp. 102, 215).

D. La teoría utopista de la sociedad es el último de los rasgos que conforman la estructura de la sociedad tribal como enemiga del pluralismo. En esta cosmovisión se da por cierto que la sociedad humana debe perseguir un modelo perfecto o patrón ideal, que puede encontrarse al comienzo o al final de la historia (Popper, 2006, pp. 101, 352). Así, el hombre no es libre para establecer sus propios fines ni los de sus sociedades, sino que estos están ahí como modelos o como resultados necesarios (Popper, 2006, p. 177). La desviación de los derroteros que llevan a los esquemas originales son indeseables o inútiles (Popper, 2006, p. 166), de ahí el rechazo al cambio y la consiguiente represión de sus posibles fuentes en todos los ámbitos de la vida humana (Popper, 2006, p. 215).

Con la revisión de estos elementos de la sociedad tribal queda claro que el pluralismo no tiene cabida en su seno. Pasemos ahora a la revisión de los componentes de la sociedad abierta que constituyen los genes del pluralismo. La sociedad liberal sustenta el pluralismo en diversos componentes culturales que pueden conjuntarse bajo tres rubros, a saber: a) la teoría individualista de la sociedad y la justicia, b) la visión humanitaria de la sociedad y c) la tradición racional o crítica de la verdad.

a. La teoría individualista y liberal de la sociedad y la justicia, propia de la cultura abierta, considera que cada ser humano debe ser valorado individualmente; la dignidad individual es el valor fundamental y el basamento de toda sociedad (Popper, 2006, p. 117). Se entiende que cada individuo tiene derecho 
a modelar su propia personalidad y vida en la medida en que no afecte las libertades de los demás (Popper, 2006, p. 181). Cada miembro de la sociedad es único y puede ser diferente del resto. La comunidad es entendida como una sociedad de hombres libres (Popper, 2006, pp. 286, 456). Las instituciones sociales tienen como finalidad primaria la protección de la libertad de cada uno de sus miembros (Popper, 2006, p. 109), pero nunca la utilización de los mismos como meros medios para alcanzar el bien de la comunidad total (Popper, 2006, pp. 117-121). La liberación del pensamiento de los seres humanos individuales de la tutela de la autoridad y el prejuicio es el objetivo primario de la cultura abierta. La preservación, generación y desarrollo de aquellas instituciones que sean compatibles con la libertad individual es un objetivo ineludible de este modelo cultural (Popper, 2006, p. 12). Popper afirma que "la gran revolución espiritual que condujo al derrumbe del tribalismo y al advenimiento de la democracia no fue sino la emancipación del individuo" (Popper, 2008, p.117). La responsabilidad personal sobre las decisiones individuales deriva de esta visión, en la que cada ser humano tiene, al menos parcialmente, su destino en sus propias manos y, por tanto, la obligación de responder por las consecuencias de sus actos (Popper, 2006, p. 189). En la sociedad liberal la estabilidad y preservación del orden social no es un propósito institucional; por el contrario, la valoración positiva de la libertad individual permite que muchos miembros se esfuercen válidamente por alcanzar los sitios sociales más elevados ocupados por otros (Popper, 2006, p. 190) y reconoce el derecho a la reconformación del esquema social de acuerdo con los intereses legítimos de cada generación.

b. Visión humanitaria de la sociedad. Hemos visto que la sociedad tribal tiene como principios el colectivismo, la jerarquización y el utopismo. Por el contrario, en la cultura abierta la interpretación de la ética humanitaria exige una interpretación igualitaria e individualista de la justicia (Popper, 2006, p. 121). La igual valoración individual y el liberalismo personal dan paso a diversos principios de la cultura abierta, entre los que se cuentan los de libertad de pensamiento, expresión y participación en el debate cívico, que se entienden como inherentes a todos los miembros de la humanidad. La libertad cultural individual es, igualmente, un gen del pluralismo. 
c. La tradición racional o crítica de la verdad. Ya hemos dicho en este trabajo que la sociedad abierta es una comunidad racional, lo que significa que los mecanismos de la razón son los principales instrumentos que utiliza para la resolución de todos los problemas sociales (Popper, 2006, p. 452). Aquí nos referiremos a tres rasgos claramente conformantes del pluralismo como elemento de la cultura abierta: en primer lugar, la libertad de pensamiento y manifestación de las ideas, la cual es necesaria para que el juego pueda operar. Esto implica la necesidad de estimular la creatividad y la imposibilidad de cerrar la admisión a cualquier emisor. En segundo término, está la autonomía de los argumentos que no permite la discriminación de ningún emisor. Por último, la intersubjetividad que valora al individuo y su responsabilidad personal como elementos sin los cuales el juego no puede desarrollarse.

Ahora podemos ver con claridad cómo es que, si se toma el catálogo de elementos de la cultura abierta como premisas, se puede concluir que el pluralismo es un rasgo inexorable de dicha cosmovisión. Individualismo, liberalismo, igualitarismo, responsabilidad personal y racionalismo son los genes que, en conjunto, conforman el $\mathrm{ADN}$ del pluralismo que caracteriza necesariamente a la sociedad abierta. A continuación procedemos a explicar cómo es que Häberle proyecta la valoración positiva del pluralismo y los principios que le preservan en el tipo Estado constitucional.

\section{Pluralismo y Constitución}

En la obra haberleana el pluralismo es entendido como "la diversidad de ideas e intereses en lugar de la unidad 'por decreto', es lo que hace al Estado constitucional superior frente a todas las formas de dominio totalitario [...] el pluralismo es expresión y condición de la libertad tanto individual como colectiva de los ciudadanos y los seres humanos" (Häberle, 2003, p. 198).

Al referirse a los fundamentos teóricos de la constitución democrática como modelo de la buena constitución, Häberle expresa: "Vista tal y como es, aparecerá tanto más importante cuanto más relevante sea el valor de la propia Constitución en el seno de la respectiva comunidad pluralista, entendido como "directriz suprema de la misma"' (Häberle, 2002, p. 61). Siendo que "por constitución no solo se debe aludir a la del 
Estado [...] comprende las estructuras básicas de la sociedad pluralista" (Häberle, 2002, p. 88). En la obra de Peter Häberle, en general, el Estado constitucional es la conformación jurídica de la sociedad abierta, en específico, la buena constitución es la constitución de la comunidad pluralista (Häberle, 2002, p. 76).

En este sistema jurídico-político, Häberle considera que la base de los procesos constitucionales se encuentra en lo que denomina "pensamiento posibilista o pluralista alternativo" (Häberle, 2002, p. 63), en la medida y en tanto que se mantenga abierto --de espíritu-- en el sentido filosófico popperiano del término 'apertura de espíritu' (Häberle, 2002, p. 61). Para Häberle, "el racionalismo crítico, cuyos procedimientos se basan en premisas de avanzar conjeturas y someterlas a refutaciones -trial and error-, es el primer factor que cabe señalar aquí, hallándose muy próximo al pensamiento posibilista..." (Häberle, 2002, p. 62). Para el maestro alemán "tales principios comienzan en la educación preescolar infantil y concluyen en el pluralismo científico epistemológico de las facultades universitarias" (Häberle, 2002, p. 113). Häberle entiende que estos mecanismos intelectuales y argumentativos son "medios para conservar y recrear continuamente condiciones de libertad para los ciudadanos en vistas a la consecución de un justo y razonable equilibrio de intereses" (Häberle, 2002, p. 74).

En la teoría haberleana la democracia se entiende como el gobierno temporal en el que los gobernantes y las políticas públicas son elegidos y sustituidos mediante el uso de los procedimientos del racionalismo crítico (Häberle, 2000, p. 130), mientras que las constituciones democráticas en conjunto son una "familia de constituciones de base pluralista", es decir, de todas aquellas en las que el principio, la base y el fundamento "inmanente" lo constituye el propio pluralismo" (Häberle, 2000, p. 113).

En la estructura argumentativa hasta aquí referida puede observarse claramente por qué y cómo es que los genes pluralistas de la sociedad abierta de Popper componen los fundamentos teóricos de la constitución democrática de Peter Häberle (Valadés, 2006, p. 48). El análisis de una sola figura nos ha permitido alcanzar nuestro objetivo, consistente en dilucidar el grado y manera en que la obra de Popper hace realizable y caracteriza el trabajo académico de Peter Häberle; sin embargo, vale la pena seńalar que algunos otros conceptos y elementos del tipo Estado constitucional en los que se encuentra al pluralismo de la sociedad abierta como sustento son: la división 
de poderes en sentido amplio, la división vertical del poder público, el principio de tolerancia, el principio de laicidad del Estado, el principio del Estado cultural, la protección de minorías y la protección de las culturas autóctonas.

\section{Aplicaciones de la SOCIEDAd ABIERTA Y SUS ELEMENTOS EN LA OBRA DE HÄBERLE}

Hasta ahora hemos visto cómo los rasgos de la sociedad abierta son compatibles con el tipo Estado constitucional y cómo es que el principal de sus elementos, el racionalismo crítico, determina tanto el desarrollo de las realizaciones teóricas de Häberle como el producto de las mismas, el arquetipo Estado constitucional. Ahora nos ocuparemos de otra forma de determinación del pensamiento de Popper en los trabajos de Häberle, el desarrollo de conceptos por aplicación tomando como base diversos elementos de la sociedad abierta. Nuevamente nuestro análisis será seccional y meramente ejemplificativo, solo referido a la teoría de la interpretación constitucional.

\section{Las sociedades abiertas}

Es notorio que la sociedad abierta de Popper estimula a Häberle a desarrollar una teoría interpretativa de los textos constitucionales; el solo nombre utilizado lo expresa: la Sociedad Abierta de los Intérpretes Constitucionales (Valadés, 2006, p. 138). Lo que no resulta obvio es la forma en que la aplicación teórica se ejecuta. Procedamos a observar esta relación. En primer lugar presentaremos los rasgos de la cultura abierta que son relevantes para el tema, de nuevo en contraste con los respectivos de la sociedad cerrada. A la luz de estos elementos podremos analizar la teoría de la interpretación constitucional tradicional y la teoría propuesta por Häberle.

La sociedad abierta, a la cual ya hicimos aquí referencia genérica, puede adjetivarse así debido a que presenta, entre otras, las siguientes características: a) Racionalismo y apertura en el tiempo y en el espacio de los procesos cívicos. La socialización y los mecanismos por los que se toman las decisiones cívicas son regidos por un juego argumentativo racional e intersubjetivo, en el que los enunciados participantes pueden provenir de cualquier individuo. El juego se encuentra permanente e infinitamente 
abierto; b) Individualismo y liberalismo. La autonomía intelectual de todo individuo da sustento a la concepción de la comunidad como sociedad política de hombres libres. La unidad en los acuerdos básicos en lo social se entiende como medio para proteger la autonomía individual en lo privado; c) Igualdad. La participación en toda argumentación se hace en condiciones de igualdad; las características particulares del emisor son irrelevantes; d) Apertura interpretativa e histórica. Se reconoce la necesidad y la legitimidad de la reinterpretación constante de la realidad pasada, presente y futura mediante los mecanismos de la razón; e) Cosmopolitismo. Existe una visión universalista y fraternal de la humanidad. En efecto, la relajación de las fronteras culturales es un rasgo natural.

En oposición, la sociedad cerrada presenta los siguientes rasgos: 1) Tribalismo. Generación de grupos sociales cerrados. 2) Autoritarismo. Las decisiones obedecen a la voluntad arbitraria del poderoso. 3) Dogmatismo. Se desprecia la racionalidad humana poniendo acento en la irracionalidad. En este ambiente, las razones para la acción provienen de tabúes inmutables que se institucionalizan; la verdad se concibe como definitiva y universal, e impera el argumento de autoridad, por lo que las ideas son impuestas y no se admite su debate a la luz de la racionalidad. La crítica es, pues, rechazada y suprimida. 4) Miedo al cambio y a la inestabilidad. La seguridad, la estabilidad, la certidumbre y el orden son valorados por temor a lo desconocido e indeterminado.

A la luz de estos perfiles, analicemos ahora la teoría tradicional de la interpretación constitucional contrastándola con la propuesta por Häberle.

\section{Interpretación gremial vs. Interpretación abierta}

Häberle afirma que la tradición de la teoría de la interpretación constitucional ha permitido que la comunidad de individuos que puede interpretar válidamente los textos constitucionales pueda calificarse como una sociedad cerrada. Los rasgos que lo llevan a esa consideración son los siguientes: en primer lugar, la regla de reconocimiento del conjunto de participantes en el juego, que admite solo a los juristas, en primera instancia, y, en última, solo a los jueces constitucionales. Es decir que la interpretación constitucional ha sido considerada propia y exclusiva de aquellos que 
dominan los métodos interpretativos canónicos y, en definitiva, de los formalmente autorizados para ello (Häberle, 2003, p. 149). En segundo lugar, señala dos rasgos de la matriz disciplinaria de los profesionales de la interpretación constitucional. Por un lado, afirma que la tradición vigente ha entendido que la interpretación es el medio correcto para obtener un dato previo, simple y terminado que es la norma (Häberle, 2002, p. 113); lo que Häberle llama la ideología de la subsunción (Häberle, 2003. p. 156). Por otro, hace ver que el paradigma dominante considera, con apego a la teoría tradicional o ingenua de la democracia representativa, que el contenido legislativo es necesariamente de carácter normativo y proviene solo del emisor oficial del texto, única entidad legitimada para ello.

El carácter cerrado de la concepción tradicional se deriva de que, a) considera cerrado el proceso de interpretación, pues estima, falsamente, que el sentido del texto sea fijado desde el momento de la emisión del mismo, con lo cual deja fuera de consideración la participación real del intérprete; b) al oscurecer la participación efectiva del intérprete en el proceso de asignación de significado, este puede conducirse veladamente, lo cual da pie para que sea la autoridad quien establezca, de manera arbitraria, el sentido del texto constitucional (Häberle, 2002, pp. 127-128. Häberle, 2002, p. 188); c) excluye a muchos de los destinatarios del texto constitucional como participantes legítimos en la interpretación del mismo; d) excluye irracionalmente fuentes de argumentos, al no admitir que las ideas de la cultura constitucional universal puedan ser utilizadas en la conformación de la realidad constitucional particular, derivada de los procesos interpretativos respectivos. Dichas características permiten que esta teoría pueda ser denominada como cerrada, esotérica o gremial (Häberle, 2002, pp. 112, 121, 127).

Häberle propone la sustitución de los rasgos de la concepción tradicional de la exégesis constitucional, por aquellos que las nuevas ideas de la teoría de la interpretación sugieren y que son compatibles con la cultura abierta. Los caracteres sugeridos son los siguientes (González Rivas, 2010. pp. 9-11):

A. Apertura interpretativa. Entendimiento de la interpretación como un proceso de asignación del significado por parte del intérprete, que necesariamente se encuentra siempre abierto y dentro de un contexto cultural (local, regional y mundial) que lo determina (Häberle, 2003, p. 156. Häberle, 2002, pp. 126, 
138-139). Dicha apertura permite la reinterpretación de los textos a la luz de las nuevas ideas de la cultura constitucional pertinente.

B. Exégesis pluralista. Admisión o reconocimiento de todos los destinatarios del texto constitucional como partícipes legítimos de la interpretación del mismo. "Todos los órganos del Estado, todos los poderes, todos los ciudadanos y los grupos" (Häberle, 2003, p. 150 y Häberle, 2001, p. 112). "Tienen acceso a él todas la fuerzas de la comunidad política” (Häberle, 2003, p. 153). Häberle entiende que cada ciudadano tiene derecho a la participación en la configuración de la cultura constitucional (Häberle, 2003, p. 158 y Häberle, 2002, p. 134). La res pública es conformada por toda la sociedad y constituye el contexto interpretativo legitimador (Häberle, 2003, p. 155 y Häberle, 2002, pp. 90-91), descripción que no pretende eliminar las diferencias funcionales de los distintos intérpretes (Häberle, 2003, p. 155). ${ }^{11}$

C. Argumentación racional. Reconocimiento y fortalecimiento de los métodos argumentativos del racionalismo crítico, tanto en los procesos públicos de conformación y transformación del texto constitucional como de asignación de significado al mismo (Häberle, 2002, pp. 88, 188). Implica el uso de la creatividad (Häberle, 2002, pp. 131, 134 y Häberle, 1998, p. 94) y los mecanismos de la razón en la conformación de la realidad constitucional (Häberle, 2003, p. 160 y Häberle, 2002, pp. 118, 133, 137-139).

D. Interpretación cosmopolita. Consideración primordial del método interpretativo comparativo sobre los métodos tradicionales. Asignación de significado al texto constitucional teniendo en cuenta la familia internacional de textos constitucionales pluralistas en sentido estricto y amplio. ${ }^{12}$ Mientras la Cons-

11 Sobre el carácter y función de los distintos intérpretes constitucionales puede consultarse: González Rivas Martínez, Pedro Daniel, "Una aproximación al Iusculturalismo de Peter Häberle”, Cuestiones Constitucionales, Revista Mexicana de Derecho Constitucional, Instituto de Investigaciones Jurídicas, unam, México, núm. 27, juliodiciembre de 2012, p. 165; específicamente el apartado III. 3 La sociedad abierta de los intérpretes constitucionales, pp. $175-177$.

12 Häberle, 2003, pp. 162-165; Valadés, 2006, p. 9; Häberle, 1997, p. 328. Sobre textos constitucionales en sentido estricto y amplio véase: González Rivas Martínez, Pedro Daniel, "Una aproximación al Iusculturalismo de Peter Häberle, p. 165; apartado III. 7, La comparación juridico-cultural como quinto método de interpretación constitucional, pp. 180-183. 
titución es entendida como la cultura constitucional real, la comparación y comunicación de realidades culturales es un medio útil para que surja y se establezca el derecho mundial emparentado, el Ius commune universal.

Concepción de la interpretación constitucional que considera que esta se encuentra abierta en cuanto al sentido del texto, respecto de las tesis válidas en la argumentación correspondiente al proceso de asignación de significado y, principalmente, respecto del círculo de los que participan en ella (Häberle, 2002, pp.133-134).

\section{Conclusiones.}

Se ha evidenciado y explicado porque las propuestas metodológica y conceptual de Peter Häberle constituyen un desarrollo de la filosofía epistemológica y teórico-política de Karl R. Popper. Resulta sostenible la afirmación de que la Sociedad Abierta de Popper es la plataforma y cimentación del Estado Constitucional häberleano. Para Häberle, el Estado constitucional y la actividad de quienes ordenan sus partes, se encuentran regulados íntegramente por el racionalismo crítico popperiano. La columna vertebral de la estructura teórica de ambos pensadores es la misma. Por una parte, Häberle profesa el racionalismo crítico en cuanto a su propia actividad académica y lo propone como método de trabajo para el estudio individual de los diversos estados y para la construcción del tipo Estado constitucional. Por otra parte, para que los elementos del tipo Estado constitucional sean admitidos como tales deben ser congruentes con los rasgos de la Sociedad Abierta y deben desarrollarse a partir de los genes culturales de esa misma cosmovisión. Los componentes de la cultura abierta son las premisas del Estado constitucional.

Mientras Popper propone la comunidad cosmopolita de hombres racionales, Häberle plantea la comunidad cosmopolita de ciudadanos. En ambos casos el objetivo es la búsqueda eterna de la justicia y la verdad a través de la razón humana; en el primer caso, todos los mecanismos culturales son abarcados; en el caso de Häberle hay una concentración en los institutos jurídico-políticos referidos y vinculados por el término "Constitución". Häberle pretende poner al servicio de la cultura abierta el herramental del que dispone su disciplina; esto pasa necesariamente por la conformación y operación de una comunidad mundial de Estados democráticos. El Estado cons- 
titucional resulta ser un instrumento para que los elementos de la Sociedad Abierta se divulguen en la cultura constitucional internacional y, en última instancia, en la cultura humana universal; es por ello que merece el calificativo de "Estado abierto".

\section{REFERENCIAS}

González Rivas Martínez, P. D. (2012), “Una aproximación al Iusculturalismo de Peter Häberle", Cuestiones Constitucionales, Revista Mexicana de Derecho Constitucional, Instituto de Investigaciones Jurídicas, UnAM, México, (27) julio-diciembre. 166-191.

González Rivas Martínez, P. D. (2010) "El método de interpretación comparatista de Peter Häberle", Crónica Judicial. Revista del Tribunal Superior de Justicia del Estado de Querétaro, México, época III, año 4. 9-11.

Häberle, P. (1997) La libertad fundamental en el Estado constitucional, trad. de Carlos Ramos y Jürgen Saligmann. Lima: Universidad Católica del Perú.

Häberle, P. (1998) Libertad, igualdad, fraternidad, 1789 como historia, actualidad y futuro del Estado constitucional, trad. de Ignacio Gutiérrez Gutiérrez. Madrid: Trotta.

Haberle P. (2000). Teoría de la constitución como ciencia de la cultura. Granada, España.: Emilio Mikunda.

Haberle P. (2001). La imagen del ser humano dentro del estado constitucional. Lima, Perú.: Pontificia Universidad Católica del Perú.

Häberle, P. (2002) Pluralismo y constitución, trad. de Emilio Mikunda-Franco. Barcelona: Tecnos.

Häberle, P. (2002) Constitución como cultura. Artículos seleccionados para Colombia, trad. de Ana María Montoya. Instituto de Estudios Constitucionales Carlos Restrepo Piedrahita. Bogotá: Universidad del Externado de Colombia.

Häberle, P. (2003) El Estado constitucional, trad. de Héctor Fix Fierro. México: Instituto de Investigaciones Jurídicas, UNAM.

Häberle, P. (2006) Verdad y Estado constitucional, traducción de Guillermo José Mañón Garibay. México: UnAM. 
Häberle, P. (2006) El federalismo y el regionalismo como forma estructural del Estado constitucional, trad. de Joaquín Brage Camazano. México: Instituto de Investigaciones Jurídicas, UNAM.

Popper, K. R. (2006) La Sociedad abierta y sus enemigos, trad. de Eduardo Loedel. Barcelona: paidós, surcos.

Popper, K. R. (2008), Conjeturas y refutaciones, el desarrollo del conocimiento cientifico. Trad. de Néstor Míguez. Barcelona: Paidós, Básica.

Popper, K. R. (2008) La lógica de la investigación cientifica, trad. de Víctor Sánchez de Zavala. Madrid: Tecnos.

Valadés, D. (2006), Compilador, Conversaciones académicas con Peter Häberle. México: Instituto de Investigaciones Jurídicas, UnAM. 